\title{
Developing EFL University Students' Vocabulary Retention and Some Listening \\ Comprehension Skills through Some \\ Electronic Devices Thesis ${ }^{*}$ \\ Al-Shimaa Salah El-Din Attia Al-Feky* shimaelfeky5@gmail.com
}

keywords: Skills - Vocabulary - Retention - Electronic Devices - Listening - Comprehension.

The ability to comprehend spoken language entails complex, instant and simultaneous processing of different types of information. To comprehend spoken language, one needs to coordinate sounds, vocabulary, grammatical structures, and background knowledge. Many scholars therefore asserted the difficult nature of listening. Empirically, several factors have been found to contribute to the problematic nature of EFL listening (Kurita, 2012).

Listening comprehension entails online processing (Gonen, 2009) of linguistic and background information, and coping with the uncontrollable speed of delivery. It therefore involves a great deal of mental processes.

*Thesis (M.A.), Faculty of Education, Department of Curriculum and Instructional Technology, Zagazig University.

* Lecturer Assistant of the English Language Department, University Requirement Unit, Misr University for Science \& Technology. 
The process of vocabulary retention involves not only meanings (sentences) but also form (association of ideas). This information is important for a learner when he/she faces new vocabulary. One of the most important ideas in word retention is that of priming (Nemati, 2009).

Electronic dictionaries (ED) do not have the structural and spatial limitations of paper dictionaries, can recover and blend information based on the specifications of the user. One of the features of using ED is learning English through usage of combined words such as collocation (Boonmoh, 2012).

\section{The problem:}

Concerning the significance of EFL listening comprehension skills, first year student of Faculty of Foreign Languages and Translation of MUST University lack these skills. In addition, they have obstacles in vocabulary retention. To validate the problems students, face during their listening comprehension skills and vocabulary retention .

\section{Questions:}

More specifically, the study addressed the following questions:

The main question;

How can some EFL listening comprehension skills and vocabulary retention of Faculty of Foreign Languages and Translation of MUST University first year students be developed via electronic devices?

The main question can be sub-divided into the following questions: 
1-What are the required EFL listening comprehension skills of Faculty of Foreign Languages and Translation of MUST University?

2-What is the current level of Faculty of Foreign Languages and Translation of MUST University of EFL vocabulary retention?

3-What is the effect of electronic devices on enhancing EFL listening comprehension skills of Faculty of Foreign Languages and Translation of MUST University?

5-What is the effect of electronic devices on enhancing EFL vocabulary retention of Faculty of Foreign Languages and Translation of MUST University?

\section{Purposes:}

This study utilized electronic devices in developing listening comprehension skills and vocabulary retention of Faculty of Foreign Languages and Translation of MUST University first year students.

\section{Hypotheses:}

The present study attempted to validate the following hypotheses:

1-There is a statistically significant difference between the mean of scores of the post-test administration of listening comprehension of the control and experimental groups in favor of the experimental group.

2-There is a statistically significant difference between the mean of scores of the pre post-administration of the listening comprehension to the experimental and control groups in favor of the electronic devices. 
3- There is a statistically significant difference between the mean of scores of the post-test administrations of the vocabulary retention test to the experimental and control groups in favor of the experimental group.

4-There is a statistically significant difference between the means of scores of the pre post-administrations of the vocabulary retention to the experimental group in favor of the post results.

\section{Participants:}

The participants of the study consisted of a selected a group of sixty students of Faculty of Foreign Languages and Translation of MUST University of $6^{\text {th }}$ of October city. They were divided into two groups (experimental and control), each group consisted of thirty students.

\section{Design:}

The quasi-experimental design was used for comparing two groups; the control group who utilized electronic devices.

\section{Instruments:}

The following instruments were utilized in order to achieve the purpose of the study:

1-The listening comprehension skills checklist.

2- A listening comprehension skills test.

3-A listening comprehension skills Rubric.

4-The vocabulary retention checklist.

5- A vocabulary retention test.

6- The vocabulary retention Rubric. 


\section{Procedures:}

The following procedures were traced for carrying out the study:

1-Reviewing the literature and the previous studies related to listening comprehension skills and vocabulary reetntion.

2-Designing the listening comprehension skills checklist and vocabulary retention checklist then presenting them to jurors to verify their validity.

3-Identifying the most rrequired listening comprehension skills and vocabulary reetntion according to the jury's panel opinions.

4-Preparing the final version of the listening comprehension skills test and vocabulary retention for implementation.

5-Submitting the tests to a jury to verify their validity.

6-Modifying and writing the tests according to the panel of jury's opinions in their final form.

7-Applying the listening comprehension test and vocabulary retention test on a special sample student to verify their reliability.

8-Designing the program.

9-Testing the participants (experimental control groups).

10-Implementing the electronic program to the experimental group, at the same time, applying it to the control group via the regular methods of teaching.

11-Post testing of the participants (experimental control groups).

12-Analyzing the results statistically.

13-Interpreting the results in light of the research hypotheses. 
14-Presenting conclusions, recommendations and suggestions for further research.

\section{Results of the study:}

It can be resulted that electronic devices were effective in developing the study group listening comprehension skills and vocabulary retention.

\section{Suggestions for further research}

The present study suggests the following researches:

1-Utilizing electronic devices in developing other language skills.

2-Administering electronic devices in teaching other areas in primary, preparatory and secondary stages.

\section{Recommendations:}

Based on the previous results, the present study recommends the following:

1- Listening comprehension skills should receive suitable attention in order to be developed in all stages.

2-Electronic devices should be integrated in the curriculum and in classroom practices. 